\title{
A Changing Australian Population Demographic: The Role of Rural Nurses
}

\section{Karen Francis ${ }^{*}$}

School of Nursing, Midwifery and Indigenous Health Charles Sturt University Wagga, Deputy Chair Australian and New Zealand Council of Nursing and Midwifery Deans, Australia

*Corresponding author: Karen Francis, Professor, Head School of Nursing, Midwifery and Indigenous Health Charles Sturt University WaggaWagga Deputy Chair Australian and New Zealand Council of Nursing and Midwifery Deans, Australia, Tel: +61 2 69334110; Fax: +61 0409719707;kfrancis@csu.edu.au

Received date: November 18, 2014; Accepted date: November 26, 2014; Published date: November 28, 2014

Copyright: (c) 2014 Francis K. This is an open-access article distributed under the terms of the Creative Commons Attribution License, which permits unrestricted use, distribution, and reproduction in any medium, provided the original author and source are credited.

\section{Introduction}

The Australian population is ageing, a trend occurring globally in developed world nations [1]. This change in the population demographic has led to policy reform as a mechanism to stem the predicted increased demand on the health care system particularly for chronic disease management and palliative care [2-4]. Australia's population is approximately 23 million and is concentrated in the major cities on the coastal fringe in each state and territory. Those who do not live in these cities reside in rural areas. Research demonstrates that rural Australians are disadvantaged and have inequitable access to a range of services including health care compared to city counterparts [1]. Ageing rural people are at increased risk of being further disadvantaged as the demand for available health care intensifies.

Nurses are the largest group of health professional's accounting for $50 \%$ of the entire health workforce [5]. This percentage increases the more remote the practice context, and in some communities nurses are the sole health care professionals locally available. These nurses provide lifespan inclusive health care. Nurses are well distributed throughout all areas of Australia and as such have been identified as the most appropriate members of the health workforce to deliver necessary health services to rural populations [5].

\section{Background}

Australia is a large island continent with the majority of the population concentrated in the major cities located on the coastal fringe. Population density decreases with increasing distance from these cities.

The 'tranny of distance' is often quoted to capture the implications of living in rural Australia. Travelling great distances to access services is necessary for many rural Australians. Not surprisingly road trauma and deaths are higher for rural populations than those that reside in major cities. Rural Australians have shorter life expectancy, experience higher rates of chronic diseases such as diabetes mellitus, hypertension, asthma, hay fever and rhinitis, ischaemic heart disease, stroke, dementia, mental health conditions and some cancers [1]. Despite the disadvantages living in rural Australia has advantages. Wide-open spaces, friendly people, sunshine and a slower pace of life are often cited as the attractions of living in the 'bush' [2].

\section{Rural Nursing Workforce}

Nurses are the mainstay of health care in rural Australia. They are the most widely distributed group of health care professionals. They are employed by public, private and not for profit organisations. In some rural communities nurses are the sole providers of health care. While they may work without local medical and allied health support, access to health colleagues is enabled through the use of information communication systems and 'fly in fly out' health care services. Nurses' roles vary according the context in which they work however the essence of practice remains constant. Wholistic care that has the person, group, community as the focus characterizes practice.

Many have commented that rural health practice is generalist in orientation $[2,3,6,7]$. Rural nurses by necessity must be able to care effectively for people of all ages and be adaptable as the resources available are variable depending on the practice context. Their knowledge and skill base is broad and their practice is inclusive of primary, secondary and tertiary levels of care. They are often well known and respected by community that is both a benefit and a challenge [8]. As nurses are the primary providers of health care in rural settings they are well placed to deliver necessary health care.

\section{The Rural Practice Environment}

Working in the rural environments is a challenge requiring nurses to be multi-skilled. Nurses are relatively evenly distributed in all geographic regions of the country in contrast to medicine and allied health professionals who are concentrated in the major capital cities [5]. Recruitment and retention of medical doctors to rural communities has not been successful despite a range of initiatives that have included the establishment of rurally based medical schools, rural medical scholarship programs and training incentives [5]. Knowledge and skills therefore must be extensive to enable nurses to meet need. Advanced assessment and diagnostic skills are fundamental for practice in these contexts. Knowing the community and being able to communicate with individuals, groups and community is a necessary talent. Moreover, being adaptable and able to work in practice environments that may be collegiate and resource poor is a common feature of working in 'the bush' [7,8]. Rural nurses may work autonomously although they collaborate with others. Their work is diverse and traverses the lifespan. The contexts of practice include but are not limited to acute, aged, palliative and primary health care, forensic and mental health services. In all settings, nurses work to a broad scope of practice. The use of information and communication technology is an expanding feature of their practice. Accessing information through evidence based databases and other electronic resources and consulting with peers who are not locally based is a common feature of their practice [9]. Many isolated rural communities are also serviced by specialist health care providers who 'fly-in-fly out'. Local nurses collaborate with these interdisciplinary health care teams ensuring community access [10]. 


\section{Changing Population Demographic and the Practice of Rural Nurses}

Australia like many nations is an ageing society. It is predicated that the number of people aged 65 and over will rise by 91 per cent and the number aged 85 and over in the next twenty years [1]. The implications of such as a dramatic population change include a significant increase in the burden of chronic diseases [1]. For rural Australians accessing health care is already compromised. As the population ages it is likely that the rural aged will experience greater health inequity unless there are significant policy and health service planning changes.

The Australian Government identified chronic disease as the most significant health issue impacting the population. Affirmative actions to reduce the burden of disease have been implemented including a move toward preventative health care to limit future generations developing preventable diseases [4]. Nurses, particularly rural nurses, have a significant role in the management of chronic disease and in providing palliative care. Rural nurses are often well known and trusted by the communities in which they live and work [11]. These nurses know the community and are able to harness available resources to support individuals, groups and the community [2,3]. Many rural nurses work in settings that incorporate primary, acute, aged, palliative and rehabilitative care. These nurses are ideally situated to promote health and wellbeing thus effecting positive health care outcomes that are inclusive of 'good death'.

\section{Advancing nursing and models of care}

To reduce the burden of disease models of care must be reviewed and new models developed that ensure care is person centred and capitalizes on the human, fiscal and physical resources available [4]. Advancing nursing practice is heralded by the Australian government as the most appropriate method for securing the heath of rural Australians. Modifying policy to support enhanced practice has commenced. Many nurses are undertaking programs of study to meet eligibility to prescribe medicines to improve service delivery [12]. Nurse practitioners are recognized as advanced practice nurses. These nurses enhance access to care particularly in rural settings and evidence indicates and that they improve clinical outcomes $[13,14]$.

\section{Conclusion}

Living in rural Australia is both a privilege and a challenge. Open spaces, small close-knit communities and a slower pace of life are characteristically cited as positives associated with living in rural locations. Conversely, these same locations are often significant distances from many services such as education and health that people who reside in major cities take for granted. Nurses predominantly provide health care services in rural Australia. Their practice is generalist and lifespan inclusive. They work collaboratively with other health professionals however the more remote the settings the more likely it is that non-nurse members of the health care team may not be based locally. Reliance on communication and information systems to support health care is an important feature of nurse's practice in these settings. Consistently, the Australian Government highlights the ageing of the Australian population and the impact of chronic diseases predicted to balloon over the next two decades as a major challenge. Nurses have been identified as the primary providers of health care in rural settings and therefore the most appropriate members of the health care team to deliver care to optimize health outcomes. Reconceputalising models of care and capitalizing on the opportunities available to advance practice are strategies that rural nurses must engage in to ensure the future wellbeing of rural Australians.

\section{References}

1. Australian Institute of Health and Welfare (AIHW). (2014). Australia's health 2014: The 14th biennial health report of the Australian Insitute of Health and Welfare. Canberra

2. Francis, K., Chapman, Y., Hoare, K., \& Birks, M. (2013) Australia and New Zealand, Community as Partner, theory and practice in Nursing (2nd ed.). Sydney: Wolters Kluwer,/ Lippincott, Williams \& Wilkins.

3. Francis K, ChapmanY, Hoare K, Birks M (2013) Promoting healthy partnerships with rural populations. In K. Francis, Y. Chapman, K. Hoare \& M. Birks (Eds.), Australia and New Zealand, community as partner theory and practice in nursing (pp. 372-385). Sydney: Wolters Kluwer, Lippincott, Williams \& Wilkins.

4. Larter A (2014) White leaves nursing school for policy. Nursing Review.

5. Health Workforce Australia (HWA) (2012) Health Workforce 2025: Doctors, nurses and midwives - Volume 1. (Vol. 1). Adelaide

6. Dade Smith J (2004) Australia's Rural and Remote Health: A social justice perspective. Croyden, Victoria: Tertiary Press.

7. Francis KL, Mills JE (2011) Sustaining and growing the rural nursing and midwifery workforce: Understanding the issues and isolating directions for the future. Collegian, 18(2), 55-60.

8. Hegney D, Francis K, Mills J (2014) Rural health. In K. Francis, Y. Chapman \& C. Davies (Eds.), Rural nursing: The Australian context (pp. 18-33). Port Melbourne: Cambridge

9. Francis K, Chapman Y, Davies C (2014) Rural Nursing: The Australian Context. South Melbourne: Cambridge

10. Birks M, Mills J, Francis K, Coyle M, Davis J, Jones J (2010) Models of health service delivery in remote or isolated areas of Queensland: A multiple case study. Australian Journal of Advanced Nursing, 28(1), 25-34.

11. McConnell-Henry T, Chapman Y, Francis K (2010) Rural nursing: Looking after people you know. Australian Nursing Journal, 17(8), 42.

12. Sullivan E, Francis K, Hegney D (2010) Triage, treat and transfer: Reconceptualising a rural practice model. Journal of Clinical Nursing, 19(11-12), 1625-1634.

13. Della P, Zhou H (2009) Report on the evaluation of the nurse practitioner role in NSW (D. o. Health, Trans.) (pp. 30). Perth: Curtin University of Technology.

14. Eley D Fallon A, Gorman D, Fahey P, Rogers-Clark C, Hegney D (2006) Key Issues in Rural Health: Perspective of Health Service Providers in Queensland (pp. 71). Toowoomba: University of Southern Queensland. 